\title{
SEMIT: ASAL MUASAL BAHASA ARAB
}

\author{
Melisa Rezi \\ Sekolah Tinggi Agama Islam Darul Qur'an Payakumbuh \\ e-mail: melisarezi96@gmail.com
}

Amrina

Institut Agama Islam Negeri Batusangkar e-mail: amrina@iainbatusangkar.ac.id

\begin{abstract}
Abstrak: Semit merupakan gabungan dari bahasa-bahasa berdekatan yang dinisbahkan kepada Sam bin Nuh (Sam adalah salah satu dari anak-anak Nuh) dalam kitab Safar Takwin (kitab Kejadian) diceritakan tentang tiga orang keturunan Nuh (Ham, Sam, dan Yafit). Dalam kitab tersebut juga disebutkan keturunan Sam bin Nuh, yaitu Elam, Asyur, Arfakasyad, dan Aram, dari mereka inilah berkembang bahasa dan bangsa Semit itu. Adapun cabang-cabang bahasa Semit dan bangsanya tergambar dalam "Syajarah AlLughaatus Saamiyah" yaitu bagian utara adalah Kan'aniyah (Ajritiyah, Kan'an Kuno, Muabiyah, Finiqiyah, dan Ibriyah) dan Aramiyah. Sedangkan bagian selatan terbagi kepada Arab Selatan (Ma'iniyah, Sabaiyah, Hadramiyah, Quthbaniyah, Habsyiah) dan Arab Utara yang terbagi kepada Arab Baidah (Tsamudiyah, Shafawiyah, Lihyaniyah) dan Arab Baqiyyah (Hijaziyah dan Tamim) Bahasa yang tertua dari keluarga bahasa Semit adalah Bahasa Arab, karena bahasa Arab adalah bahasa Semit yang terdekat dengan bahasa Semit lama. Penutur bahasa-bahasa itu berasal dari keturunan Sam anak Nuh a.s. Negri asal bangsa Semit adalah Arab.
\end{abstract}

Kata Kunci: Bahasa Arab, Penutur, Semit, Sam.

Abstract: Semit is a combination of adjacent languages that is attributed to Sam bin Nub (Sam is one of Nub's sons) in Safar Takwin book (Genesis book) about the story of Nub's three sons (Ham, Sam, and Yafit). The book also explains about the descent of Sam bin Nuh, namely Elam, Asyur, Arfakasyad, and Aram, who became the ancestor of Semit race and language. The brances of Semit race and language are described in "Syajarah Al-Lughaatus Saamiyah". In the north is Kan'aniyah (Ajritiyah, old Kan'an, Muabiyah, Finiqiyah, and Ibriyah) and Aramiyah. In the south is divided into south Arabic (Ma'iniyah, Sabaiyah, Hadramiyah, Quthbaniyah, Habsyiah) and north Arabic which is classified into Baidah Arabic (Tsamudiyah, Shafawiyah, Libyaniyah) and Baqiyyah Arabic (Hijariyah and Tamim). The oldest language of Semit is A rabic, because it is the nearest language to the old Semit. The language speakers are the descent of Sam, the son of Nub a.s, and the origin country of Semit race is Arabian.

Key words: Arabic language, speakers, Semit, Sam

\section{PENDAHULUAN}

Semit merupakan kumpulan bahasabahasa yang muncul sejak lama. Bahasa Arab termasuk dalam kelompok bahasa Semit atau lebih populernya disebut rumpun bahasa Semit. Rumpun bahasa (fashaail al-lughawiyah) adalah golongan besar bangsa (bahasa) yang sama asal dan jenisnya (Sakholid Nasution, 2017: 60). Sebagian bahasa Semit tersebut 
masih digunakan jutaan orang dan memiliki kekayaan budaya dan sastra tersendiri. Sementara sebagian lagi telah punah seiring waktu.

Semua pengkaji filologi dan linguistik Arab percaya bahwa bahasa Arab berasal dari rumpun bahasa Semit. Malah terdapat beberapa pandangan ahli linguistik Arab yang mengatakan kemungkinan bahasa pertama yang dituturkan oleh orang-orang Samiyyah ini juga adalah bahasa Arab Kuno (al-'arabiyyah al-qadimab). Bahasa Arab juga merupakan satu-satunya bahasa Semit dengan jumlah penutur yang paling banyak melebihi 150 juta (Bernard Comrie, 1998: 24).

Bangsa Semit merupakan suatu bangsa yang hidupnya berpindah-pindah tempat (nomaden) untuk mencari kehidupan yeng lebih baik dari tempat sebelumnya, Berbagai penelitian telah dilakukan untuk mencari kebenaran tentang bahasa tertuanya dan kawasan asal bangsa Semit. Peran peneliti dalam hal ini sangatlah penting untuk menambah pengetahuan bagi masyarakat dunia. Namun berbeda-pendapat para ahli dalam menentukannya.

\section{PEMBAHASAN}

\section{Bangsa Semit}

Istilah Semit diberikan kepada bangsa Aramiyah, Finiqiyah, 'Ibriyah, Arabiyah, Yamaniyah, dan Babiliyah-Asyuriyah (Abdul Wahid Wafy: 6). Bahasa Semit istilah yang merupakan gabungan dari bahasa-bahasa yang berdekatan yang dinisbahkan kepada Sam bin Nuh (Sam merupakan salah satu dari anak-anak Nuh) (Ahmad Muhammad
Qodur, 1999: 47). Adapun orang pertama yang memberikan istilah/ penamaan ini terhadap bangsa-bangsa tersebut adalah seorang ahli dari Jerman yang bernama Scholazer pada akhir abad ke-18 tepatnya pada tahun 1798 (Mahmud Fahimy Hijazy, 2003: 135), yang dikutip dalam kitab Safar Takwin (kitab Kejadian), dari tiga orang keturunan Nuh (Ham, Sam, dan Yafit). Adapun bangsa-bangsa tersebut merupakan keturunan dari anak cucu mereka. Dalam kitab Safar Takwin (kitab Kejadian) juga disebutkan keturunan Sam bin Nuh, yaitu Elam, Asyur, Arfakasyad, dan Aram (Abdul Wahid Wafy: 47).

Nuh (Ibrani: ñij, Nūḥ; Tiberias: nַ;; Arab: Nub) (sekitar 3993-3043 SM) adalah seorang rasul yang diceritakan dalam Taurat, Alkitab, dan Al-Quran. Nuh diangkat menjadi nabi sekitar tahun 3650 SM. Diperkirakan ia tinggal di wilayah Selatan Irak modern.

Dalam Islam, Nuh adalah nabi ketiga sesudah Adam, dan Idris. Ia merupakan keturunan kesembilan dari Adam. Ayahnya adalah Lamik (Lamaka) bin Metusyalih| Mutawasylah (Matu Salij) bin Idris bin Yarid bin Mahlail bin Qainan bin Anusyi bin Syits bin Adam. Nuh dilahirkan pada saat ayahnya berumur 182 tahun (Kej. 5:28; 1Taw 1:4). Nuh adalah orang ketiga yang memiliki umur terpanjang, mencapai 950 tahun (Kej. 9:2829). Namanya juga tercatat dalam silsilah Yesus di Lukas 3:36. Antara Adam dan Nuh ada rentang 10 generasi dan selama periode kurang lebih 1642 tahun.

Nuh hidup selama 950 tahun. Ia mempunyai istri bernama Wafilah, sedangkan beberapa sumber mengatakan istri Nuh adalah Namaha binti Tzila atau 
Amzurah binti Barakil dan memiliki empat orang putra, yaitu Kan'an, Yafit, Sam dan Ham, hanya tiga orang yang selamat dari bencana banjir karena taat serta mengikuti ajaran yang dibawa ayahnya. Adapun seorang anaknya lagi yang tertua, yaitu Kan'an, tewas tenggelam. Nuh merasa sedih karena anaknya tidak mau mengikuti ajarannya. Sedangkan menurut Hasan al-Bashri berpendapat bahwa Kan'an adalah anak tiri Nuh yaitu anak dari isterinya yang durhaka. Namun Alkitab hanya mencatat, ia memiliki 3 anak laki-laki Sam, Ham, dan Yafit. Kitab Kejadian mencatat, pada zamannya terjadi air bah yang menutupi seluruh bumi hanya ia sekeluarga (istrinya, ketiga anaknya, dan ketiga menantunya) dan binatang-binatang yang ada di dalam bahtera Nuh yang selamat dari air bah tersebut. Setelah air bah reda, keluarga Nuh kembali merepopulasi bumi. Setelah bahtera itu selesai, Kitab Kejadian menggambarkan bahwa air merendam bumi selama 150 hari lamanya dan setelah itu air mulai surut. Setelah Nuh diselamatkan, Allah mengadakan perjanjian dengan Nuh dan memberkatinya. Inilah perjanjian yang pertama dikenal dan bersifat universal karena meliputi seluruh umat manusia. Sedangkan di dalam Alquran pada surat Nuh ayat 25 menggambarkan bagaimana umat-umat yang durhaka pada masa nabi Nuh dan ditenggelamkan oleh Allah tanpa ada yang menolong mereka.

Menurut Muhammad Sirhan bahwa Nuh mempunyai empat orang anak, yaitu Sam, Ham, dan Yafit serta Yam. Yang terakhir inilah menolak naik perahu ayahnya dengan mengatakan: "Saya akan menyelamtkan diri sendiri ke sebuah Gunung dimana aku bisa lepas dari bahaya air". Maka ia tertimpa oleh siksa Tuhan, ia termasuk orang-orang lain yang tenggelam (Muhammad Sirhan, 1956: 6-7).

Jadi, dapat disimpulkan bahwa berbeda pendapat ulama tentang anak Nabi Nuh yang tenggelam. Akan tetapi mereka sepakat terhadap 3 orang anak nabi Nuh yang hidup.

Kini tinggal tiga anak Nuh yang masih hidup, dan dari merekalah terjadi berbagai ras di bumi ini dengan turun temurun. Adapun orang-orang yang naik perahu selain anak-anak Nuh telah membuahkan keturunan. Di antara ahli Tarikh dan ahli Tafsir mengatakan bahwa sewaktu perahu Nuh sampai pada bukit Judy di Jazirah Arab, penumpang-penumpang perahu itu turun ke daratan sekitarnya, kemudian mereka bertempat tinggal di situ. Kemudian setelah menjadi sempit mereka menyebar berkelompok-kelompok, susul-menyusul terpencar ke seluruh muka bumi (Muhammad Sirhan, 1956: 7).

Selanjutnya keturunan Sam menempati bagian Barat, Barat daya Asia dan sebelah Utara, demikian pula tersebar ke Habsyi dan lembah Nil di Afrika. (Muhammad Sirhan, 1956: 7).

Ibnu Thabari menyebutkan istri Sam bernama Shalib binti Batawil bin Mehujael bin Akhnukh bin Qayin bin Adam dan darinya Sam menurunkan Arfaqsyad, Asyur, Lud, Elam, dan Aram.

Keturunan Ham menempati Afrika Utara, Timur dan beberapa Afrika Tengah (Muhammad Sirhan, 1956: 7). Ibnu Thabari menyebutkan istri Ham bernama Nahlab binti Marib bin Al Darmasil bin bin Mehujael bin Akhnukh bin Qayin bin Adam dan darinya Ham menurunkan 4 orang anak lakilaki, yaitu Kush, Put, Kanaan dan Misraim.

Sedangkan keturunan Yafit menjadi dua kelompok besar, sebagian menuju Asia

\section{Semit: Asal Muasal Bahasa Arab}


bagian Tenggara menjadi nenek moyang bangsa Hindu dan Cina, dan sebagian yang lain menuju daerah utara dan barat menurunkan bangsa Eropa dan cabangcabangnya, sebagian keturunan Yafit ini terkenal dengan sebutan Arian yang berasal dari kata Sanskerta kuno "aria" yang berarti luhur dan mulia. Keturunan Yafitt yang membangsakan diri dengan nama Aria ini yang membedakan diri dari unsur-unsur ras yang lebih rendah yang telah menduduki daerah India sejak permulaan sejarah (Muhammad Sirhan, 1956: 6-7). Ibnu Thabari menyebutkan istri Yafitt bernama Arbasisah binti Marazil bin Al Darmasil bin bin Mehujael bin Akhnukh bin Qayin bin Adam dan darinya Yafitt menurunkan 7 orang anak, yaitu: Gorner, Magong, Madai, Yawan, Tubal, Masekh, dan Tiras.

Adapun keturnan Nuh dan bangsabangsa mereka, serta wilayah yang mereka tempati, dapat penulis gambarkan melalui bagan dan peta berikut ini, yaitu:

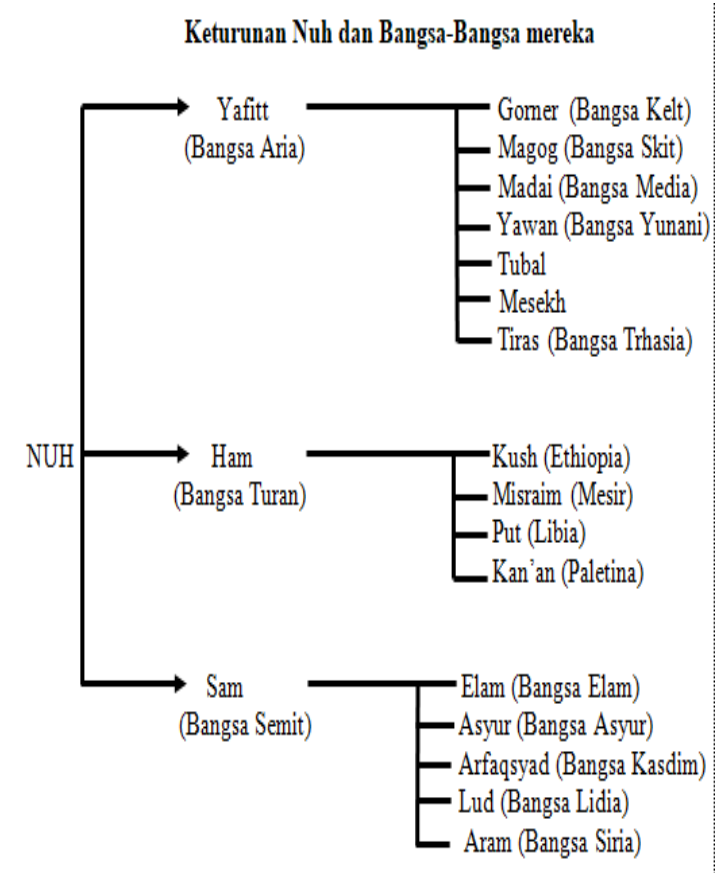

\section{Peta wilayah Keturunan Nuh}

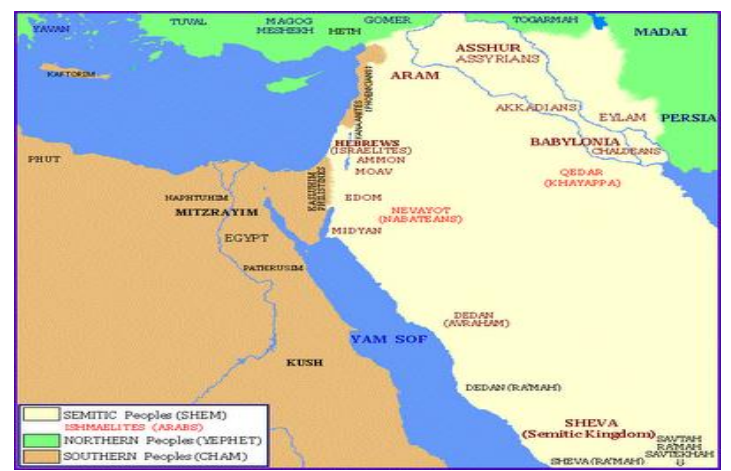

Peta di atas menggambarkan wilayah keturunan Nuh as, yang ditandai dengan tiga warna, yaitu warna hijau di bagian utara itu adalah keturunan Yafith, sedangkan warna coklat di bagian selatan itu adalah keturunan Ham, dan untuk warna krem di bagian tengah itu adalah keturunan Sam. Dari peta wilayah inilah kita bisa melihat bahwa putraputra Nuh sudah sejak semula telah membentuk bangsa mereka masing-masing. Meskipun ada pendapat yang mengatakan bahwa keturunan anak-anak Nuh telah saling berbeda sejak mula pertama. Ini tidaklah logis sebab waktu itu belum ada percampuran yang memungkinkan adanya batas yang jelas bahwa sebagian merupakan bangsa Semit yang belum bercampur darah dengan bangsa lain, dan sebagian lain bangsa Semit yang juga begitu dan demikian selanjutnya. Yang lebih logis adalah bahwa keturunan putra-putra Nuh sudah sejak semula telah membentuk satu bangsa yang sama bahasanya, rasnya maupun kehidupannya. Kemudian terjadilah pertempuran-pertempuran di antara mereka sendiri dalam masa yang lama hingga akhirnya nampak perbedaan-perbedaan antara cabang-cabang keturunan yang bermacam-macam. 
Keturunan-keturunan Sam menang di berbagai tempat, maka semua penduduk disitu akhirnya mengaku sebagai nasab atau keturunan Sam. Demikian pula yang terjadi pada Ham dan Yafitt.

Adapun keturunan dari bangsa Semit dapat kita lihat dari bahasa yang ia gunakan. Menurut al-Barkawy yang termasuk ke dalam bahasa Semit adalah bahasa Akadiyah (bagian Timur), Kan'aniyah dan Aramiyah (bagian Barat), Arab Utara, dan Arab Selatan-Habsyi (Abdu al-Fath Abdu al-Alim al-Barkawy: 43). hal ini juga telah digambarkan oleh Subhi Shalih dalam bukunya dengan istilah "Syajarah $A l$ Lughaatus Saamiyah" yaitu:

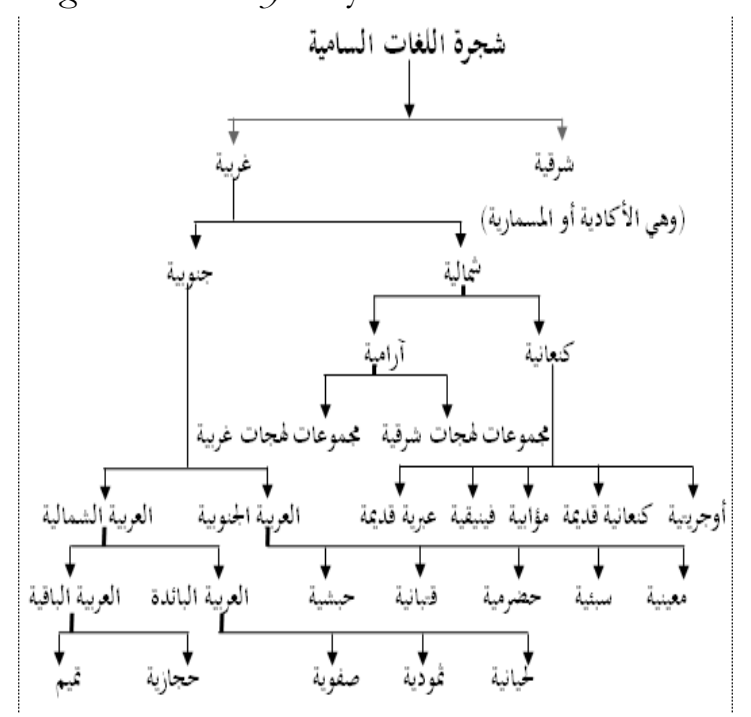

(Subhi Shalih : 71)

Ketika diperhatikan deskripsi "Syajarah Al-Lughaatus Saamiyah", maka akan terlihat tidak hanya cabang-cabang bahasa Semit tetapi juga bangsanya, yang mana bahasa Arab kita sekarang termasuk salah cabang bahasa Semit (bagian dari bahasa Semit). Adapun bahasa Semit itu pada awal perkembangannya terbagi kepada Timur dan Barat. Pada bagian Timur terdapat bahasa
Babiliyah-Asyuriyah (Akadiyah) yang diambil dari nama negri Akad oleh para ahli modern Fiqh Lughah, sedangkan dahulu nama negri itu adalah Isfiniyah/ Mismariyah. Sedangkan pada bagian Barat terbagi kepada dua bagian, yaitu:

1. Utara

a. Kan'aniyah

Kan'aniyah adalah bahasa kabilah Arab yang terletak di utara barat, dan penduduknya bertempat di Palestina dan sebagian Laut Tengah, yang terjadi kira-kira tahun 2000 SM. Adapun Kan'aniyah yang dimaksud disini adalah bukanlah Kan'an anak Nabi Nuh saudara Sam, Ham dan Yafit yang tenggelam, akan tetapi Kananiyah disini merupakan keturunan Sam yang tebagi kepada beberapa bahasa yaitu Ajritiyah, Kan'an Kuno, Muabiyah, Finiqiyah, dan Ibriyah.

Di bawah ini akan dijelaskan sebagai berikut:

1) Ajritiyah adalah bahasa tertua di kelompok Kan'aniyah yang terkenal dengan bahasa prasastinya tahun 1926

2) Kan'an Kuno adalah bahasa yang ditulis dengan bahasa Akadiyah,

3) Muabiyah adalah lahjah orangorang Muabiyun, yang mereka dari keturunan Luth bin Akhi Ibrahim al-Khalil

4) Finiqiyah adalah bahasa yang telah sampai kepada kita melalui ukiran/ prasasti dan potongan uang yang ditemukan oleh orang-orang penduduk kuno Finiqiyah.

5) Ibriyah adalah lahjah Ka'aniyah terpenting yang sampai kepada kita melalui kitab-kitab kuno.

\section{7 | Semit: Asal Muasal Bahasa Arab}


b. Aramiyah

Aramiyah diambil dari sebagian peninggalan-peninggalan AsyuriyahBabiliyah. Kabilah-kabilahnya sudah berhijrah dari Jazirah (sebuah pulau) ke negri Babil-Asyur kira-kira antara abad 14-12 SM (Subhi Shalih: 49-50).

2. Selatan

a. Arab Selatan

1) Ma'iniyah adalah lahjah yang dinisbahkan kepada Mineens, yang menempati negri Arab, di bagian Selatan Yaman.

2) Sabaiyah adalah lahjah yang dinisbahkan pada orang-orang Saba', yang mana mereka mendirikan satu kerajaan mereka di atas reruntuhan kerajaan Ma'iniyah. Adapun kota Ma'rib merupakan ibukota dari kerajaan Saba' dan di dalam sejarah kerajaan ini termasuk ibukota yang sangat besar.

3) Hadramiyah adalah lahjah yang dinisbahkan kepada Hadramaut. Hadramaut merupakan kerajaan besar yang punya peradaban gemilang, akan tetapi Saba' tetap lebih kuat dari pada kerajaan Hadramaut.

4) Quthbaniyah adalah lahjah yang dinisbahkan kepada Quthban, dia adalah kerajaan besar yang didirikan di daerah pesisir yang terdapat di daerah 'Udn.

5) Habsyiah, adapun bahasa-bahasa terpentingnya adalah Ja'ziyah, Amhariyah, dan Tayjiryah. Sedangkan bahasa tertuanya adalah Ji'ziyah atau Habsyah kuno yang mana sebagian karakteristiknya mirip dengan bahasa Arab (Subhi Shalih: 52-54).

b. Arab Utara

1) Arab Baidah: Tsamudiyah (lahjah yang dinisbahkan kepada kabilahkabilah Tsamud), Shafawiyah (lahjah yang dinisbahkan kepada negri Shafa), Lihyaniyah (lahjah yang dinisbahkan kepada kabilah Lihyan), (Subhi Shalih: 55-56). Adapun bahasa Arab Baidah yaitu bahasa Arab yang telah lenyap atau tidak sampai kepada kita. Sementara orang menyebutkan sebagai bahasa Arab prasasti, yaitu bahasa suku-suku yang telah lenyap dan riwayatnya tak diketahui sama sekali (Emil Badi' Ya'kub, 1982: 111). Menurut Sahkholid Nasution bahasa Arab Baidah sering juga disebut dengan Al-Arabiyah AnNuquusy dimana eksistensinya tidak dapat diketahui secara pasti, karena bahasa ini hanya dapat diketahui melalui analisa teks-teks atau manuskrip-manuskrip bersejarah yang masih ada (Sakholid Nasution, 2017: 63).

2) Arab Baqiyyah: Bahasa Arab Baqiyyah artinya Bahasa Arab yang sampai kepada kita melalui tulisan, karangan dan sastra, dan sampai kepada kita Alquran, Hadits (Subhi Shalih: 59), dan melalui peninggalan-peninggalan sastra Jahily oleh para penyair pada masa jahiliyah (Abdul Wahid Wafy: 107), Arab Baqiyah terbagi dua yaitu Arab 'Aribah (kaum-kaum Arab yang berasal dari keturunan Ya'rib bin Yasyjub bin Qahthan,

Melisa Rezi, Amrina 118 
atau disebut pula Qahthaniyah), dan Arab Musta'ribah (kaumkaum Arab yang berasal dari keturunan Isma'il, yang disebut pula 'Adnaniyah) ( Samy bin Abdullah al-Maghluts, 2004: 28).

\section{Bahasa Semit Tertua}

Bahasa manusia sangat banyak jumlahnya dan berbeda antara satu dengan yang lain. Jumlahnya mencapai beberapa ribu, belum termasuk bahasa-bahasa yang sudah punah. Jelaslah bahwa semua bahasa itu berasal dari sumber satu yaitu dari bahasa manusia pertama.

Para ahli berbeda pendapat tentang asal mula tanah air asli bangsa Semit, demikian juga tentang bahasa yang tertua dari keluarga bahasa Semit (Samy bin Abdullah alMaghluts, 2004: 14-15) yang dipergunakan oleh anak cucu Sam bin Nuh pada masa awal-awal sebelum mereka berpencar ke berbagai negri, namun yang asti bahwa bangsa itu dulu tentu mempunyai satu bahasa jika kita yakin bahwa bangsa itu tumbuh dari satu tempat tertentu (Muhammad Sirhan, 1956: 10).

Sebagian peneliti ada yang berpendapat bahwa bahasa yang tertua dari rumpun Semit adalah bahasa Babil, sementara yang lain, yaitu orang-orang Yahudi, beranggapan bahwa bahasa yang tertua adalah bahasa Ibrani bahkan tertua bagi umat manusia. Sementara banyak di antara para orientalis berpendapat bahwa bahasa Arab lebih dekat dengan bahasa Semit awal.

Emil Badi' Ya'kub juga mengemukakan perbedaan pendapat tentang bahasa Semit tertua ini di dalam bukunya, yaitu:

1. Di antara mereka ada yang mengatakan bahwa bahasa Ibriyah adalah bahasa ibu
Semit, dan ia adalah bahasa tertua di dunia.

2. Di antara mereka ada yang berpendapat bahwa Asyuriyah-Babiliyah adalah bahasa Semit pertama.

3. Kelompok ketiga ini berpendapat bahwa bahasa Arab adalah bahasa Semit yang terdekat dengan bahasa Semit lama (Emil Badi' Ya’kub, 1982: 110-111).

Tidak satupun dari pendapat-pendapat di atas dapat dijadikan kebenaran karena bahasa-bahasa Semit telah menjalani proses yang cukup panjang dalam perkembangannya sebelum sampai ilmu ulama dalam mengetahuinya (Abdul Wahid Wafy : 15). Adapun pendapat-pendapat itu hanya merupakan kesimpulan-kesimpulan yang tidak lengkap dipandang dari segi ilmu pengetahuan, karena kekurangan data bahasa yang lengkap sehingga penelitian tersebut sulit dilakukan (Wildan Taufiq, 2015: 46). Adapun semua bahasa telah mengalami perkembangan, persentuhan dan pembudayaan yang mengakibatkan perubahan ciri dan keistimewaankistimewaannya. Tentu saja bahasa Semit tertua atau yang terdekat dengan bahasa Semit awal telah dihadapkan pada factorfaktor yang memungkinkan adanya perubahan dari aslinya, hingga akhirnya antara bahasa yang masih ada dengan yang pertama telah semakin jauh perbedaannya (Muhammad Sirhan, 1956: 10-12).

\section{Asal dari Para Penuturnya}

Bahasa Semit adalah bahasa-bahasa Semit yang dipergunakan oleh bangsabangsa dari keluarga besar Sam beserta cabang-cabangnya yang berasal dari dia pula.

Dalam waktu lama para ahli telah memperoleh petunjuk tentang hubungan antara keluarga-keluarga bahasa itu, yakni setelah ditemukan peninggalan-peninggalan 
dan dokumen-dokumen tertulis dari bahasabahasa Asyur, Phunesia, Yaman Kuno dan Kanasiah Habsyi. Dengan itu mereka telah berhasil menganalisir rumus-rumusnya, hingga mereka sependapat tentang adanya kesamaan-kesamaan antara bahasa-bahasa itu dengan bahasa-bahasa Semit (Muhammad Sirhan, 1956: 9).

Sebagian dari penutur bahasa-bahasa itu berasal dari keturunan yang sama, jadi nasab mereka berpangkal dari Sam anak Nuh a.s, namun banyak pula orang-orang berbicara dengan bahasa itu bukanlah keturunan Sam, hal ini disebabkan karena pindahnya bahasa Semit ke negri mereka akibat perpindahan orang-orang keturunan Sam itu ke daerah mereka (Abdul Wahid Wafy: 9-10), mungkin pula karena penguasa mereka, atau karena pengaruh perdagangan maupun politik dimana percaturan bahasanya dimenangkan oleh bahasa Semit.

Pada mulanya bangsa-bangsa Semit pastilah berasal dari bahasa yang sama. Tapi sangatlah sulit bagi para peneliti untuk menentukan letak yang tepat dari negri itu, sukar pula bagi mereka menentukan kapan orang-orang Semit ini hidup sebelum mereka terpencar-pencar menjadi suku-suku yang berbeda (Muhammad Sirhan, 1956: 9).

Menurut Ramadhan Abdul Tawwab, berbeda pendapat ulama dalam menetapkan negri asal bangsa Semit, diantaranya:

1. Negeri asal bangsa Semit adalah Afika, pendapat ini dikemukakan oleh Theodor Noldeke. Ia mengatakan bahwa "Keserumpunan Bangsa Semit dan Bangsa Hamit menunjukkan bahwa kawasan asal bangsa Semit adalah Afrika".
2. Negeri asal bangsa Semit adalah Armenia pendapat ini dikemukakan oleh seorang peneliti dari Perancis bernama Renan. Ia mengatakan bahwa "Bangsa Semit berasal dari berbagai kawasan di Armenia". Renan mendasarkan teorinya ini pada Kitab Perjanjian Lama (Ramadhan Abdul Tawwab, 1994: 3839), yaitu ayat 10 butir $30(10 / 30)$ berbunyi : "Daerah kediaman mereka terbentang dari Mesa ke arah Sefar, yaitu Pegunungan di sebelah timur (Pegunungan Ararat di Armenia)".

3. Negeri asal bangsa Semit adalah Babilonia pendapat ini dikemukakan oleh dua orang peneliti yang bernama Ignatius Guidi dan Frets Hummel. Mereka mengatakan dalam tulisannya yang diterbitkan di Roma pada tahun 1879 bahwa: "Kawasan asal Bangsa Semit adalah hilir Sungai Eufrat yaitu Lembah Daratan Irak (Babilonia) " (Ramadhan Abdul Tawwab, 1994: 3940).

4. Negeri asal bangsa Semit adalah Arab yang dinamakan juga dengan "Semit induk", dan banyak para ahli yang berpendapat bahwa bahasa Arab paling dekat dengan Semit induk atau disebut juga dengan bahasa Arab merupakan bahasa tertua bangsa Semit (Muhammad Husein Ali Yasin, 1980: 643). Pendapat ini juga dikemukakan oleh salah satu orientalis yaitu Esbiringer, dkk. Mereka mengatakan bahwa "Jazirah Arab merupakan kawasan asal Bangsa Semit". Esbiringer, dkk mengatakan hal demikian karena mereka memiliki beberapa argumen yang mendukung teorinya tersebut, diantaranya kawasan

Melisa Rezi, Amrina 120 
subur di antara Sungai Tigris dan Sungai Eufrat selalu didatangi Suku Badui dari padang pasir yang melakukan imigrasi, orang Arab yang secara genetika belum tercampur dengan bangsa lain, memiliki bentuk fisik yang sama.

Di antara pendapat yang masyhur dari para ahli dalam masalah ini antara lain:

1. Bahwa negeri asal orang-orang Semit adalah Barat Daya Asia, yaitu di negri Hijaz, Yaman Najd, dan sekitarnya. Di antara yang berpendapat demikian adalah beberapa orientalis misalnya Renan dari Prancis dan Brockelman dari Jerman.

2. Bahasa mereka berasal dari Babilonia, banyak dari ahli-ahli sejarah bangsa Arab serta ahli-ahli tafsir menganut paham ini. Beberapa orientalis yang lain juga menganut paham ini.

3. Bahwa asal mereka adalah daerah Kan'an. Pendapat ini merupakan pendapat sebagian ahli dari bangsa Yahudi, karena rasa kedengkian dan ambisi untuk kemegahan sejarahnya. Paham ini telah berhasil mempengaruhi beberapa sarjana Arab hingga mereka menganut paham Yahudi dalam soal ini.

Di samping pendapat di atas kita masih menjumpai pendapat lain yang menyatakan bahwa asal mula bangsa Semit adalah negeri Habsyi, ada pula yang mengatakan di Afrika Utara. Pendapat lain juga mengatakan asal mula bangsa Semit adalah Armenia yang berdekatan dengan perbatasan Kurdistan (Muhammad bin Ibrahim Ahmad, 2005: 79).

Menurut Wildan Taufiq (2015),Tiap golongan dari paham-paham di atas telah mengajukan berbagai dalil, namun belum juga ada yang sampai pada tingkat dalil yang memuaskan yang dituntut oleh peneliti secara objektif, dan sampai sekarang belum ada yang bisa membuktikan.

\section{PENUTUP}

Berdasarkan uraian pada bagian pembahasan, penulis menyimpulkan bahwasanya bangsa Semit adalah bangsa yang dinisbahkan kepada Sam bin Nuh, yang merupakan salah satu dari anak-anak keturunan Nuh Dari sinilah kita bisa mengetahui bahwa bahasa Arab yang sampai kepada kita sekarang merupakan bagian dari rumpun bahasa Semit. Para ahli berbeda pendapat tentang asal muasal tanah air asli bangsa Semit dan bahasa tertuanya, hal ini disebabkan semua bahasa anggota rumpun Semit telah melewati fase-fase yang panjang, sehingga sangat mustahil jika ada suatu bahasa tunggal di wilayah-wilayah yang berbeda, dan juga karena kekurangan datadata bahasa yang lengkap sehingga penelitian tersebut sulit untuk dilakukan.

\section{DAFTAR RUJUKAN}

Ahmad, Muhammad bin Ibrahim, Fiqh Lughab (Mafhumah-Maudhu'atuhQadhayah). 2005 M/1426 H. Beirut: Dar ibnu Khuzaimah.

al-Barkawy, Abdu al-Fath Abdu al-Alim. tt. Muqaddimah fi Figh al-Lughah alArabiyah wa al-Lughaat al-Samiyah. Kairo: Jami'ah al-Azhar.

Hijazy, Mahmud Fahimy. 2003. Asas Tlmi alLughah al-Arabiyah. Kairo: Dar alTsaqofah.

al-Maghluts, Samy bin Abdullah, al-Athlas alTarikby li Sirati al-Rasul. 2004 M/1425 H. Riyadh: Maktabah al-'Tbykan.
121 Semit: Asal Muasal Bahasa Arab 
Nasution, Sahkholid. 2017. Pengantar Linguistik Arab. Sidoarjo: CV Lisan Arabi.

Qodur, Ahmad Muhammad, Madkhal ila Figh al-Lughah. 1999 M/1326 H Damaskus: Dar al-Fikr.

Shalih, Subhi. tt. Dirasat fi Figh Lughah. Beirut: Dar 'Ilmu al-Malayiin.

Sirhan, Muhammad, Fiqhullughah (terjemahan Hasyim Asy'ari). 1956 M-1376 H. Riyadh: Fakultas Bahasa Arab.

Taufiq, Wildan. Fiqib Lughah (Pengantar Linguistik Arab). 2015. Bandung: CV. Nuansa Aulia.
Tawwab, Ramadhan Abdul, Fushulfi Figh alArabiyah. 1994 M/ 1415 H. Kairo: Maktabah al-Khanijy.

Wafy, Abdul Wahid. tt. Figh al-Lughah. Kairo: Dar Nadhoh Mesir.

Ya'kub, Emil Badi'. 1982Fiqh al- Lughah alArabiyah wa Khashoisuba. Beirut: Dar alTsaqofah al-Islamiyah.

Muhammad Husein Ali Yasiin. 1400 H/1980 M. al-Dirasat al-Lughawiyyah 'inda al-Arab ila Nihayat al-Qarni alTsalits. Beirut: Dar al-Maktabah alHayat.

http://www.Kitab kejadian/sejarah umat manusia/ kemah, bait, dan istana.com 